\title{
Rhinometric evaluation of nasal cavity geometry and its relation to the upper arch transverse distance
}

\section{João Batista Paiva ${ }^{(a)}$ \\ Adriana Silva Alves ${ }^{(b)}$ \\ Annelise Nazareth Cunha \\ Ribeiro(b) \\ José Rino Neto(a) \\ Solange Mongeli de Fantini(c)}

(a) Associate Professor; (c)PhD, Professor

- Department of Orthodontics, School

of Dentistry, University of São Paulo, São

Paulo, SP, Brazil.

(b) Dental Clinician, São Paulo, SP, Brazil.

\begin{abstract}
The objective of this study was to evaluate children's respiratory patterns in the mixed dentition, by means of acoustic rhinometry, and its relation to the upper arch width development. Fifty patients were examined, 25 females and 25 males with mean age of eight years and seven months. All of them were submitted to acoustic rhinometry and upper and lower arch impressions to obtain plaster models. The upper arch analysis was accomplished by measuring the interdental transverse distance of the upper teeth, deciduous canines (measurement 1), deciduous first molars (measurement 2), deciduous second molars (measurement 3 ) and the first molars (measurement 4). The results showed that an increased left nasal cavity area in females means an increased interdental distance of the deciduous first molars and deciduous second molars and an increased interdental distance of the deciduous canines, deciduous first and second molars in males. It was concluded that there is a correlation between the nasal cavity area and the upper arch transverse distance in the anterior and mid maxillary regions for both genders.
\end{abstract}

Descriptors: Nasal cavity; Dental arch; Acoustic rhinometry; Dental models; Respiration.
Corresponding author:

João Batista de Paiva

Av Prof Lineu Prestes, 2227

Cidade Universitária

CEP 05508-000 - São Paulo - SP

E-mail: jbpaiva@usp.br 


\section{Introduction}

When nasal breathing is compromised and oral breathing becomes predominant, the airflow and pressure in the oral and nasal cavities are modified, causing alterations in the development of these structures. Among the most common results of these alterations is the development of a long and narrow upper arch. ${ }^{1,2}$

It is said that the predominantly nasal respiratory pattern contributes to the craniofacial structures balanced growth. ${ }^{3-5}$ Shanker et al. ${ }^{5}$ (2004) wrote that oral breathing individuals have often been associated with many unfavorable characteristics in craniofacial development. In this study, it was concluded that the upper dental arch width among the nasal breathing group was significantly bigger than in the oral breathing group.

Other authors, ${ }^{6,7}$ however, reported that there is no significant association between craniofacial morphology and the respiratory pattern, and that additional and well controlled studies should still be done.

The respiratory pattern has been diagnosed in part by clinical observations, according to the literature. The acoustic rhinometry, introduced by Hilberg et al., has been described as a reliable method to analyze the respiratory pattern..$^{2,8-12}$

The clinical value of this exam is associated with its ability of measuring reliably the geometry of the nasal cavity. The exam is presented in a Cartesian graph, in which it is possible to accurately localize the transversal areas from 0 to $54 \mathrm{~mm}$ in depth..$^{8-12}$ The graph shows the minimum transversal area values observed from the nostril toward the nasopharynx. The readings describe the nasal respiratory way capacity, that is, the observed degree of nasal obstruction. The method is based on analysis of the sound waves reflected inside the nasal cavity, taking into account the sound wave incidence and reflection properties.

The objective of this study was to evaluate the respiratory pattern in children in the mixed dentition by means of acoustic rhinometry and its relation to the upper arch width development.

\section{Materials and Methods}

Fifty white children, 25 females and 25 males with a mean age of eight years and seven months, were examined. These patients were chosen randomly from a sample of enrolled ones to be submitted to orthodontic treatment at the School of Dentistry, University of São Paulo, without previous evaluations of their respiratory pattern or their upper arch shape. The requirements for the sample selection were not having undergone orthodontic treatment and or surgery, palatine and/or pharynx tonsillectomy.

In the present study, acoustic rhinometry exams were performed using the RhinoScan ${ }^{\circledR}$ (Rhinometrics A/S - Assens, Funen, Denmark) and upper plaster models.

The acoustic rhinometry exam is made in a static, rapid, and non invasive manner, without nasal flow. A probe is utilized, coupled to the nostrils' individual adapters to transmit and receive the sound from the electronic source inside the nasal cavity. The narrowest nasal cavity area is measured and standardized as the minimal cross-sectional area (MCA), and the relation of this narrowness with the respective localization throughout the nasal cavity is established. Normally, these area values are given in two moments known as: MCA1 and MCA2. In this study only MCA1 values were used.

The exams were done with the patient correctly and comfortably positioned on the chair, leaning the head, avoiding any possible head deflection or extension. At the beginning of the examination, the patient was asked to interrupt his or her respiration so that the sound waves penetrated the nasal cavity and allowed the calibration that would generate the graph. The exam was repeated until producing three green curves for each nostril. For this study, the average of these three readings was used.

Two exams were performed: the first being without a vasoconstrictor, and the second exam, approximately 15 minutes after the use of a vasoconstrictor (nasal decongestant - oxymetazoline hydrochloride $0.25 \mathrm{mg} / \mathrm{ml}$ ), applied after the first exam.

Two trained operators accomplished the exams. The performance of the acoustic rhinometry exam and the work sheet with the results are shown in figures 1 and 2 respectively. 
In this study, even though the acoustic rhinometry exam was performed with and without a vasoconstrictor, only the average values found for the nasal cavity minimum transversal area (MCA1) without the vasoconstrictor were used, thus aiming to analyze the patient in his or her normal daily life. Before beginning the examination, no evident nasal inflammation was detected.

Impressions of the upper and lower dental arches were made for each patient with Orthoprint ${ }^{\circledR}$ alginate (Zhermack - Badia Polesine, Rovigo, Italy) us-

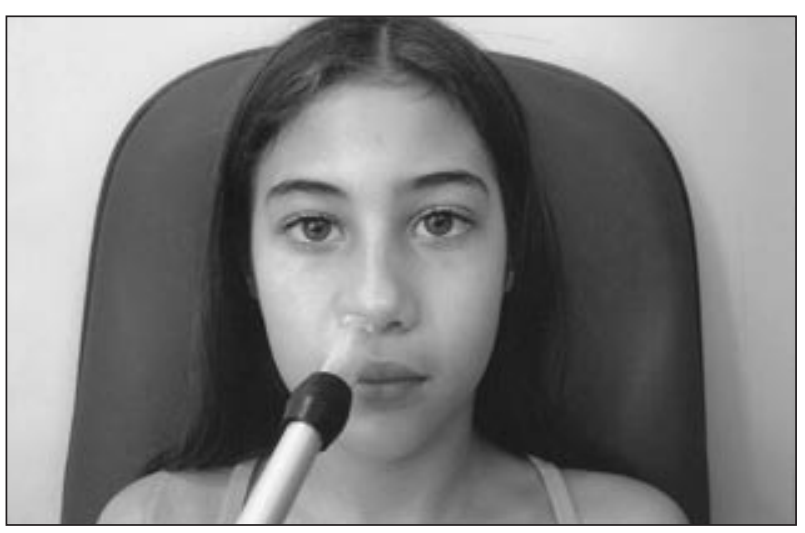

Figure 1 - Acoustic Rhinometry exam.
Figure 2 - Work sheet with the acoustic rhinometry results.

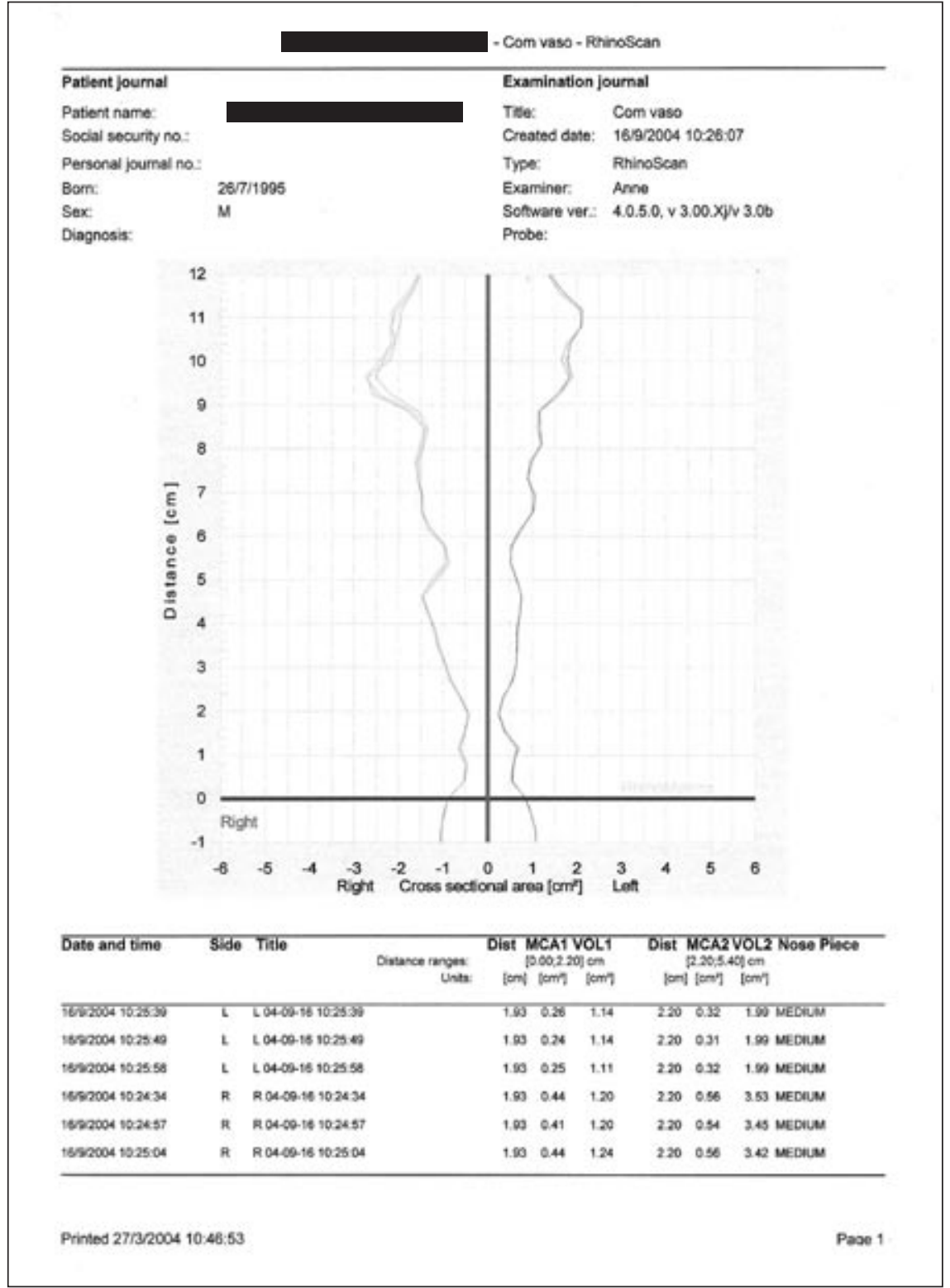


ing the proportions indicated by the manufacturer. Immediately afterwards, orthodontic plaster models were made using a ratio of $30 \mathrm{ml}$ of water to $100 \mathrm{~g}$ of powder according to the manufacturer's instructions.

The study model analysis of the upper arch was accomplished by measuring the interdental distance of the deciduous canines (measurement 1), deciduous first molars (measurement 2) and deciduous second molars (measurement 3). For these measurements, the intersection between the center of the lingual surface and the marginal gum tissue was used. For the transverse distance measurement between the upper first molars, the lingual groove and the marginal gum tissue point of intersection was used (measurement 4) as in Figure 3.

For the method's error performance, 20 plaster models were randomly chosen. The same steps were repeated with them to obtain the transversal measurement values. With the obtained values, the Dahlberg (1940) formula was applied to calculate the method's error.

The calibrations were made using a Mitutoyo digital caliper (Suzano, São Paulo, SP, Brazil) (Figure 4). The same examiner measured the plaster models.

To verify if there was a statistical difference between genders in the measurements, the $t$-Student test was applied at the $5 \%$ significance level.

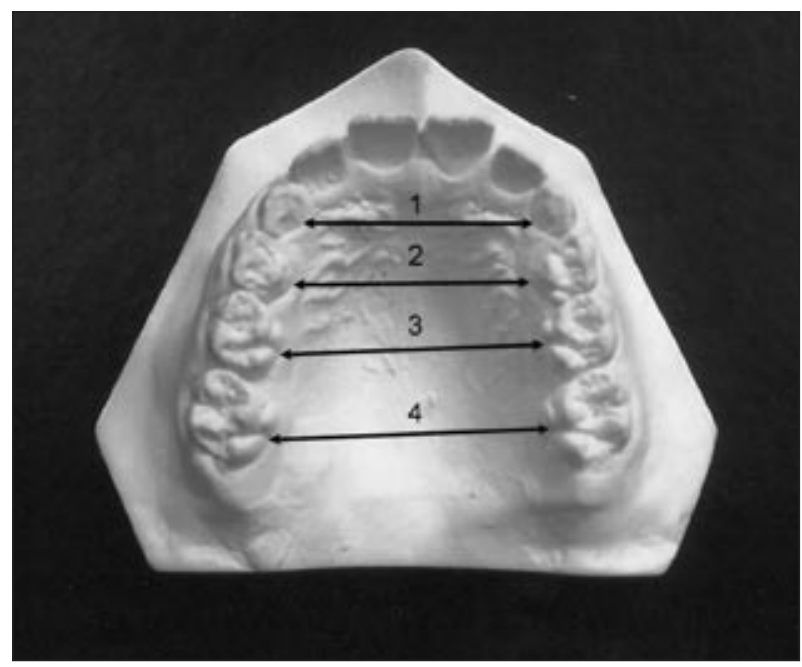

Figure 3 - Schematic drawings of measurements performed in the orthodontic study models.

\section{Results}

The acoustic rhinometry exam and the measurements taken of the plaster models, whose values presented a normal distribution, were compared by the Pearson's parametric test of linear correlation at the $5 \%$ significance level. The Pearson's correlation test results for the two genders, female and male, are represented in Tables 1 and 2, respectively.

As seen in Table 1, the interdental distances of the first deciduous molars $(\mathrm{r}=0.401$ and $\mathrm{p}=0.047)$ and second deciduous molars $(\mathrm{r}=0.406$ and $\mathrm{p}=0.044)$ in females without vasoconstrictor use were directly correlated with the rhinometric measurements of the left nasal cavity area $(p<0.05)$.

As shown in Table 2, the interdental distances of the deciduous canines $(r=0.400$ and $p=0.047)$, deciduous first molars $(\mathrm{r}=0.493$ and $\mathrm{p}=0.012)$ and deciduous second molars $(\mathrm{r}=0.435$ and $\mathrm{p}=0.030)$ were directly and significantly correlated $(p<0.05)$ with the left nasal cavity area in males.

As shown in Table 3, the average interdental distance between the permanent first molars was statistically higher in males $(p=0.036)$. The other measurements did not present average differences in relation to gender $(p>0.05)$.

\section{Discussion}

The relevance of nasal respiratory obstruction associated with orthodontics has remained a con-

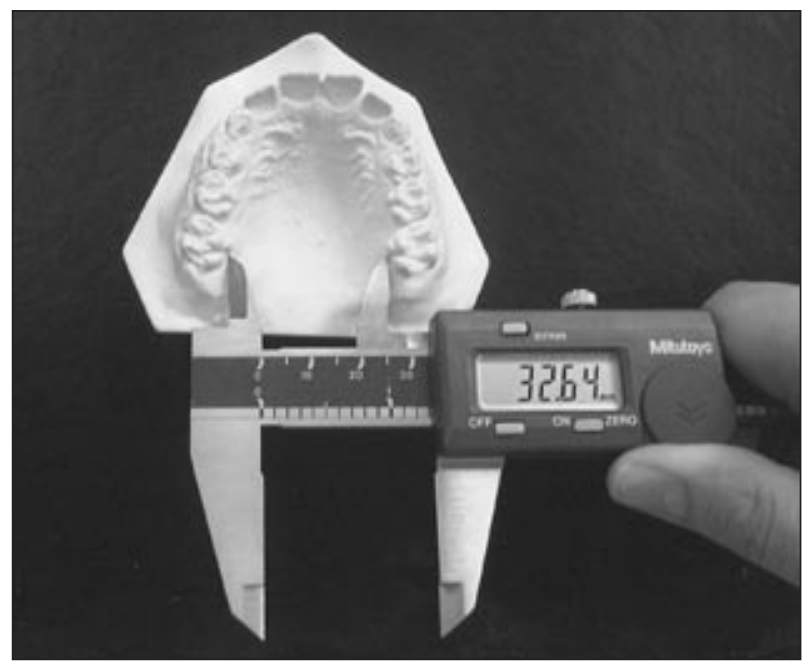

Figure 4 - Transversal measurements made with the Mitutoyo digital caliper in the orthodontic study models. 
Table 1 - Pearson's correlation results for females.

\begin{tabular}{c|c|c|c|c|c}
\hline \multicolumn{2}{c|}{ Measurement } & $\begin{array}{c}\text { Interdental distance of } \\
\text { deciduous canines }\end{array}$ & $\begin{array}{c}\text { Interdental distance of } \\
\text { deciduous first molars }\end{array}$ & $\begin{array}{c}\text { Interdental distance of } \\
\text { deciduous second molars }\end{array}$ & $\begin{array}{c}\text { Interdental distance of } \\
\text { permanent first molars }\end{array}$ \\
\hline \multirow{2}{*}{ Right W/N area } & Correlation & 0.324 & 0.307 & 0.349 & 0.367 \\
\cline { 2 - 6 } & $P$ & 0.114 & 0.135 & 0.087 & 0.071 \\
\hline \multirow{2}{*}{ Left W/N area } & Correlation & 0.311 & 0.401 & 0.406 & 0.185 \\
\cline { 2 - 6 } & P & 0.131 & 0.047 & 0.044 & 0.376 \\
\hline
\end{tabular}

W/V: without vasoconstrictor.

Table 2 - Pearson's correlation results for males.

\begin{tabular}{l|c|c|c|c|c}
\hline \multicolumn{2}{c|}{ Measurement } & $\begin{array}{c}\text { Interdental distance of } \\
\text { deciduous canines }\end{array}$ & $\begin{array}{c}\text { Interdental distance of } \\
\text { deciduous first molars }\end{array}$ & $\begin{array}{c}\text { Interdental distance of } \\
\text { deciduous second molars }\end{array}$ & $\begin{array}{c}\text { Interdental distance of } \\
\text { permanent first molars }\end{array}$ \\
\hline \multirow{2}{*}{$\begin{array}{l}\text { Right WN } \\
\text { area }\end{array}$} & Correlation & 0.191 & 0.271 & 0.125 & -0.100 \\
\cline { 2 - 6 } & $P$ & 0.361 & 0.190 & 0.552 & 0.635 \\
\hline \multirow{2}{*}{ Left W/N area } & Correlation & 0.400 & 0.493 & 0.435 & 0.178 \\
\cline { 2 - 6 } & P & 0.047 & 0.012 & 0.030 & 0.395 \\
\hline
\end{tabular}

W/V: without vasoconstrictor.

Table 3 - Description and results of the t-Student test comparing the measurements between genders.

\begin{tabular}{|c|c|c|c|c|c|c|c|}
\hline Measurement & Gender & Average & Standard deviation & $\mathrm{N}$ & Value of $t$ & $d f$ & $\mathrm{p}$-value \\
\hline \multirow{2}{*}{$\begin{array}{l}\text { Interdental distance of } \\
\text { deciduous canines }\end{array}$} & Feminine & $24.67 \mathrm{~mm}$ & 1.81 & 25 & \multirow{2}{*}{-1.93} & \multirow{2}{*}{48} & \multirow{2}{*}{0.059} \\
\hline & Masculine & $25.90 \mathrm{~mm}$ & 2.63 & 25 & & & \\
\hline \multirow{2}{*}{$\begin{array}{l}\text { Interdental distance of } \\
\text { deciduous first molars }\end{array}$} & Feminine & $26.42 \mathrm{~mm}$ & 2.42 & 25 & \multirow{2}{*}{-1.45} & \multirow{2}{*}{48} & \multirow{2}{*}{0.154} \\
\hline & Masculine & $27.39 \mathrm{~mm}$ & 2.31 & 25 & & & \\
\hline \multirow{2}{*}{$\begin{array}{l}\text { Interdental distance of } \\
\text { deciduous second molars }\end{array}$} & Feminine & $30.36 \mathrm{~mm}$ & 3.12 & 25 & \multirow{2}{*}{-1.69} & \multirow{2}{*}{48} & \multirow{2}{*}{0.097} \\
\hline & Masculine & $31.64 \mathrm{~mm}$ & 2.15 & 25 & & & \\
\hline \multirow{2}{*}{$\begin{array}{l}\text { Interdental distance of } \\
\text { permanent first molars }\end{array}$} & Feminine & $34.07 \mathrm{~mm}$ & 2.43 & 25 & \multirow{2}{*}{-2.16} & \multirow{2}{*}{48} & \multirow{2}{*}{0.036} \\
\hline & Masculine & $35.50 \mathrm{~mm}$ & 2.26 & 25 & & & \\
\hline \multirow{2}{*}{ Right W/V area } & Feminine & $0.28 \mathrm{~cm}^{2}$ & 0.10 & 25 & \multirow{2}{*}{0.51} & \multirow{2}{*}{48} & \multirow{2}{*}{0.610} \\
\hline & Masculine & $0.27 \mathrm{~cm}^{2}$ & 0.13 & 25 & & & \\
\hline \multirow{2}{*}{ Left W/V area } & Feminine & $0.29 \mathrm{~cm}^{2}$ & 0.10 & 25 & \multirow{2}{*}{-0.39} & \multirow{2}{*}{48} & \multirow{2}{*}{0.701} \\
\hline & Masculine & $0.30 \mathrm{~cm}^{2}$ & 0.11 & 25 & & & \\
\hline
\end{tabular}

W/V: without vasoconstrictor.

troversy for over a century. There are many studies that try to define a correlation between these two factors. ${ }^{2,9-12}$

The greatest challenge in establishing a relation between the respiratory pattern and the facial growth is to quantify the degree of this relation. Is the genetic factor the primary or secondary determi- nant? This question remains unanswered for more than a century. In the 1980s, Harvold et al. ${ }^{11}$ (1981) performed a study altering the respiratory pattern from nasal to oral in monkeys, using silicone to close the air passage through the nostrils, and found an alteration in the growth pattern and occlusion in relation to the control group. But, it should be empha- 
sized that humans breathe predominantly through the nose or predominantly through the oral cavity, but not exclusively by either of them. Consequently, the findings of Harvold et al..$^{11}$ (1981) can not be analyzed in a simple manner, having in mind that predominantly oral breathing patients are found, and they do not present vertical growth predominance.

Nowadays however, there is no undisputed method for registering the degree of nasal obstruction. Nonetheless, acoustic rhinometry has demonstrated to be an adequate method for the nasal area evaluation, presenting reproducible, reliable, and objective data. ${ }^{12}$

These findings are consistent with those of Çakmak et al. ${ }^{8}$ (2003), who report that acoustic rhinometry exam results and computerized tomogram results were similar, thus validating the method.

Many other authors, among them Roithmann et al. ${ }^{13}$ (1995), Zancanella, Lima ${ }^{12}$ (2004), Grymer ${ }^{10}$ (2000), Hilberg, Pedersen ${ }^{3}$ (2000), Tomkinson, Eccles $^{14}$ (1995), Çakmak et al. ${ }^{8}$ (2003), performed studies aiming to determine MCA minimum values in order to be able to distinguish between a normal nasal cavity from an obstructed one. However, most of them were accomplished with adult patients.

Hinton et al..$^{15}$ (1987) and Warren et al. ${ }^{16}$ (1988) affirmed that when the transversal section of the nasal cavity, in adults, is smaller than $0.4 \mathrm{~cm}^{2}$, there is a decrease of the air volume that passes through the nasal cavity, compromising the respiratory capacity and harming the respiration quality. An almost linear relation was found between the nasal cavity transversal area decrease and the nasal air volume decrease in this type of patient.

Believing that the nasal transversal area interferes with the respiratory pattern, and that the smaller transversal area would be in the anterior region of the nasal cavity, ${ }^{3}$ acoustic rhinometry was proposed to analyze this region, and compare it with the upper arch transversal dimensions, in an attempt to find a correlation between these factors.

The nasal geometry in children with predominantly nasal respiration and children with predominantly oral respiration was already reported by $\mathrm{Za}$ vras et al. ${ }^{2}$ (1994). The authors found statistically significant differences in the total volume of the na- sal cavity, where the oral breathers presented smaller values in relation to the nasal breathers. However, differences were not observed in relation to the nasal cavity transversal area. In this same study, it was observed that the minimum transversal area in the nasal cavity was $0.28 \mathrm{~cm}^{2}$ in males and $0.29 \mathrm{~cm}^{2}$ in females. These values were smaller than the ones found in the study performed by Vig, Zajac ${ }^{17}$ (1993), where the minimum transversal area average was $30 \mathrm{~mm}^{2}$ in males and $32 \mathrm{~mm}^{2}$ in females.

The value differences between the two studies may be associated, partially, with the studied population, knowing that in the study conducted by $\mathrm{Za}$ vras et al. ${ }^{2}$ (1994), the age samples varied from 6 to 10 years, and in that conducted by Vig, Zajac ${ }^{17}$ (1993), between 5 and 12 years. According to Warren et al. ${ }^{18}$ (1990), the air passage increases approximately $0.032 \mathrm{~cm}^{2}$ per year. This statement was made by the authors led by the study in which it was found that a transversal area average of $0.21 \pm 0.05 \mathrm{~cm}^{2}$ at 6 years of age increased to $0.46 \pm 0.15 \mathrm{~cm}^{2}$ at 14 years of age.

In the present study, where the mean age was eight years and seven months, the transversal area average was $0.28 \mathrm{~cm}^{2}$ in the right nasal cavity and $0.29 \mathrm{~cm}^{2}$ in the left nasal cavity in females, and $0.27 \mathrm{~cm}^{2}$ in the right nasal cavity and $0.30 \mathrm{~cm}^{2}$ in the left nasal cavity in males.

Analyzing the correlation between the nasal geometry and the upper arch, as shown in Table 1, females presented a much larger left nasal cavity; in addition, the interdental distances of the deciduous first molars $(r=0.401$ and $p=0.047)$ and of the deciduous second molars $(\mathrm{r}=0.406$ and $\mathrm{p}=0.044)$ were also larger in females.

As for the measurements of males, Table 2 shows that there is a correlation between the interdental distances of the deciduous canines $(r=0.400$ and $\mathrm{p}=0.047)$, of the deciduous first molars $(\mathrm{r}=0.493$ and $p=0.012$ ) and of the deciduous second molars $(\mathrm{r}=0.435$ and $\mathrm{p}=0.030)$, with the left nasal cavity. Therefore, an increased left nasal cavity area means an increased interdental distance of the deciduous canines, deciduous first molars and deciduous second molars.

Based on these correlations, it could be observed 
that results were not uniform between the relation of the nasal cavity minimum transversal area and the upper dental arch transverse distance.

In the permanent first molar area, there was no correlation between the nasal area and the upper dental arch transverse distance. However, an increased upper arch transverse distance was observed in males in relation to females, as can be observed in Table 3.

Analyzing these correlations, it can be seen that there was no uniformity of results between the left nasal cavity minimum transversal area and the upper dental arches transverse distance.

There was no correlation between the right nasal cavity minimum transversal area and the upper arch transverse distances. Even though studies in the literature do not mention the division between the right and left nasal cavity, this division was used in this research. It is interesting to observe that if the nasal cavity minimum transverse distance had been studied utilizing the average between the left

\section{References}

1. McNamara JA. Influence of respiratory pattern on craniofacial growth. Angle Orthod. 1981;51(4):269-300.

2. Zavras Al, White GE, Rich A, Jackson AC. Acoustic rhinometry in the evaluation of children with nasal or oral respiration. J Clin Pediatr Dent. 1994 Spring;18(3):203-10.

3. Hilberg O, Pedersen OF. Acoustic rhinometry: recommendations for technical specifications and standard operating procedures. Rhinol Suppl. 2000;16:3-17.

4. Principato JJ, Kerrigan JP, Wolf P. Pediatric nasal resistance and lower anterior vertical face height. Otolaryngol Head Neck Surg. 1986;95(2):226-9.

5. Shanker S, Fields HW, Beck FM, Vig PS, Vig KWL. A longitudinal assessment of upper respiratory function and dentofacial morphology in 8 - to 12 -year-old children. Semin Orthod. 2004;10(1):45-53.

6. Kluemper GT, Vig PS, Vig KW. Nasorespiratory characteristics and craniofacial morphology. Eur J Orthod. 1995;17(6):4915 .

7. Vig KWL. Nasal obstruction and facial growth: the strength of evidence for clinical assumptions. Am J Orthod Dentofac Orthop. 1998;113(6):603-11.

8. Çakmak O, Coskun M, Çelik H, Buyuklu F, Ozluoglu LN. Value of acoustic rhinometry for measuring nasal valve area. Laryngoscope. 2003;113(2):295-302. and right nasal cavity, there would have been no difference of this value for gender. The nasal cavity area in females would be the same in males, that is, $0.285 \mathrm{~cm}^{2}$.

Knowing that the facial structure is determined in the first decade of life, a longitudinal study during the growth phase may answer today's persistent questions in the near future, using more objective exams for measuring the nasal cavity, among them, acoustic rhinometry.

\section{Conclusion}

There was correlation between the left nasal cavity transversal area and the upper arch interdental distance of deciduous first molar and deciduous second molar for both genders. For the interdental distance of deciduous canines, there was correlation only in males. There was no correlation between the right nasal cavity minimum transversal area and the upper arch width.

9. Carlini D. Rinometria acústica na avaliação de pacientes entre 7 e 13 anos de idade com obstrução nasal por rinite crônica hipertrófica não infecciosa [Dissertação de Mestrado]. São Paulo: Universidade Federal de São Paulo; 1999.

10. Grymer LF. Clinical applications of acoustic rhinometry. Rhinol Suppl. 2000;16:35-43.

11. Harvold EP, Tomer BS, Vargervik K, Chierici G. Primate experiments on oral respiration. Am J Orthod. 1981,79(4):35972.

12. Zancanella E, Lima WTA. Uso da rinometria acústica como método diagnóstico. Rev Bras Otorrinolaringol. 2004;70(4):5003.

13. Roithmann R, Cole P, Chapnik J, Shpirer I, Hoffstein V, Zamel $\mathrm{N}$. Acoustic rhinometry in the evaluation of nasal obstruction. Laryngoscope. 1995;105(3 Pt 1):275-81.

14. Tomkinson A, Eccles R. External facial dimensions and minimum nasal cross-sectional area. Clin Otolaryngol Allied Sci. 1995;20(6):557-60.

15. Hinton VA, Warren DW, Hairfield WM, Seaton D. The relationship between nasal cross-sectional area and nasal air volume in normal and nasally impaired adults. Am J Orthod Dentofac Orthop. 1987;92(4):294-8.

16. Warren DW, Hairfield WM, Seaton DL, Morr KE, Smith LR. The relationship between nasal airway size and nasal-oral 
breathing. Am J Orthod Dentofacial Orthop. 1988;93(4):28993.

17. Vig PS, Zajac DJ. Age and Gender effects on nasal respiratory function in normal subjects. Cleft Palate Craniofac J. 1993;30(3):279-84.
18. Warren DW, Hairfield MW, Dalston ET. Effect of age on nasal cross-sectional area and respiratory mode in children. Laryngoscope. 1990;100:89-93. 